\title{
The Importance of Interest Rates for Forecasting the Exchange Rate
}

\author{
HILDE C. BJøRNLAND* AND HÅVARD HUNGNES \\ University of Oslo, Norway
}

\begin{abstract}
This study compares the forecasting performance of a structural exchange rate model that combines the purchasing power parity condition with the interest rate differential in the long run, with some alternative exchange rate models. The analysis is applied to the Norwegian exchange rate. The long-run equilibrium relationship is embedded in a parsimonious representation for the exchange rate. The structural exchange rate representation is stable over the sample and outperforms a random walk in an out-of-sample forecasting exercise at one to four horizons. Ignoring the interest rate differential in the long run, however, the structural model no longer outperforms a random walk. Copyright @ 2006 John Wiley \& Sons, Ltd.
\end{abstract}

KEY WORDS equilibrium real exchange rate; purchasing power parity; cointegrated VAR; out-of-sample forecasting

\section{INTRODUCTION}

The well-cited finding by Meese and Rogoff (1983), that a comprehensive range of exchange rate models was unable to outperform a random walk, has motivated numerous studies to examine the role of economic fundamentals in explaining exchange rate behaviour. More recently, however, MacDonald and Taylor (1994), Chrystal and MacDonald (1995), Kim and Mo (1995) and Reinton and Ongena (1999), among others, have found that a series of monetary models can beat a random walk in forecasting performance, at least at long horizons, using a metric like the root mean square error (RMSE) for evaluation. However, although these monetary models have proved somewhat successful in forecasting the exchange rate, they have also encountered some problems. In particular, many of the cointegrating relationships embedded in the models have taken on incorrect signs when compared to theoretical models (McNown and Wallace, 1994).

One of the basic building blocks of monetary models is the purchasing power parity (PPP) condition. However, empirical evidence for the period following the Bretton Woods fixed exchange rate system has found little to support the PPP condition. In particular, time series studies have shown that the real exchange rate is not only very volatile in the short run, but the speed of convergence

* Correspondence to: Hilde C. Bjørnland, Department of Economics, University of Oslo, Po Box 1095, Blindern, N-0317, Norway. E-mail: h.c.bjornland@econ.uio.no

Copyright (C) 2006 John Wiley \& Sons, Ltd. 
to PPP in the long run is extremely slow (see, for example, Rogoff, 1996, for a survey). ${ }^{1}$ Forecasts based on the PPP condition alone have also provided mixed results (see, for instance, Fritsche and Wallace, 1997).

The PPP condition has its roots in the goods market. Another central parity condition for the exchange rate that plays a crucial role in capital market models is uncovered interest parity (UIP). However, empirical evidence has also generally led to a strong rejection of the UIP condition in the post Bretton Woods period (see, for example, Engel, 1996, for a survey). Johansen and Juselius (1992) have suggested that one possible reason why so many researches have failed to find evidence in support of the UIP (as well as the PPP) condition is the fact that researchers have ignored the links between goods and capital markets when modelling the exchange rate. By modelling the whole system jointly, one is better able to capture the interactions between the nominal exchange rate, the price differential and the interest rate differentials, as well as allowing for different short- and longrun dynamics.

This paper examines whether a dynamic exchange rate model that combines the purchasing power parity condition with the uncovered interest parity condition in the long run can outperform a random walk model in an out-of-sample forecasting exercise. The model is applied to Norway. Previous studies of the determination of the real exchange rate in Norway have generally rejected the notion of simple PPP using conventional (time series or panel data) unit root tests (see, for example, Serletis and Zimonopoulus, 1997; Chortareas and Driver, 2001), or by testing for PPP in multivariate studies (see, for example, Jore et al., 1998; Alexius, 2001; with the exception of Akram, 2000). In a recent study, however, Bjørnland and Hungnes (2002), using a multivariate cointegrating framework, showed that a (weak) version of PPP holds against a basket of Norway's trading partners only when they incorporate the interest rate differential in the long run. However, pure PPP was rejected.

The analysis specified here relates the PPP to the UIP condition in the long run using cointegrating techniques. Having determined the long-run equilibrium relationship, a parsimonious short-run representation for the exchange rate that includes the long-run equilibrium is established. Finally, its forecasting performance is analysed and compared to alternative exchange rate specifications. In particular, the forecasting performance of an alternative structural model that identifies a long-run relationship based on pure PPP, thereby ignoring any long-run link with the interest rate differential, is also examined.

The rest of this paper is organized as follows. In the next section we discuss the hypothesis of PPP and how possible sources of deviations from PPP can be linked to the UIP condition. The third section identifies the econometric model used to estimate the long-run exchange rate, and thereafter presents the empirical results. In the fourth section we implement the long-run relationships in a short-run dynamic model, and investigate whether this model is stable over the sample. The fifth section examines whether structural models can outperform a random walk model in an out-ofsample forecasting exercise. The sixth section summarizes and concludes.

\section{LONG-RUN REAL EXCHANGE RATES}

A natural starting point for discussing the relationship between exchange rates and fundamentals is the concept of PPP. Assuming no costs in international trade, then domestic prices would equal

\footnotetext{
${ }^{1}$ The rejections have been less clear cut using panel data. See, for example, Frankel and Rose (1996), among many others. However, see O'Connell (1998) and Chortareas and Driver (2001) for critical assessments of these panel data studies. See also the recent study by Holmes (2001), who, using a new panel data unit root test, finds clear evidence against PPP. 
foreign prices multiplied by the exchange rate. The expression for PPP can then be written (in $\log$-form) as

$$
v_{t}=p_{t}-p_{t}^{*}
$$

where $p_{t}$ is the $\log$ of the domestic price, $p_{t}^{*}$ is the $\log$ of the foreign price and $v_{t}$ is the log of the nominal exchange rate. ${ }^{2}$ However, since trade is costly, PPP will not hold continuously. It is therefore informative to define the log of the real exchange rate as

$$
r_{t}=v_{t}-p_{t}+p_{t}^{*}
$$

where $r_{t}$ is the log of the real exchange rate. If PPP is valid, the real exchange rate is stationary and fluctuates around a fixed value in the short run. In a univariate framework, PPP can be tested by simply testing for whether the real exchange rate is stationary or not. Alternatively, PPP can be cast in a multivariate framework by applying cointegration methods.

The massive empirical testing of PPP has generally cast doubt on long-run PPP, either by rejecting the hypothesis that PPP follows a stationary process, or by suggesting that the real exchange rate adjusts too slowly back to a long-run equilibrium rate to be consistent with traditional PPP (the half time is normally found to be 3-4 years; see, for example, Rogoff, 1996). ${ }^{3}$ Instead, long-run deviations from PPP suggest the influence of real factors with large permanent effects, like productivity differentials, fiscal policy and other relevant variables; again see Rogoff (1996) for a survey. These factors will work through the current account, and thereby push the real exchange rate away from PPP.

However, as several authors have emphasized (see, for example, MacDonald and Marsh, 1997; Juselius and MacDonald, 2000), the balance of payment constraint implies that any imbalances in the current account have to be financed through the capital account. Shocks that force the real exchange rate away from PPP have to be captured through the movements in interest rates, since they reflect expectations of future purchasing power. Hence, massive movements in capital flows in response to interest rate differentials can keep the exchange rate away form purchasing power parity for long periods. The PPP condition in the goods market will therefore be strongly related to the central parity condition in the capital market, namely that of UIP.

According to the UIP condition, the interest rate differential will be an optimal predictor of the rate of depreciation, provided the conditions of rational expectations and risk neutrality are satisfied.

The expected gain, $g^{e}$, from investing money in Norway is given as the deviation from UIP, i.e.

$$
g_{t}^{e}=i_{t}-i_{t}^{*}-\Delta v_{t+1}^{e}
$$

where $\Delta v_{t+1}^{e}$ is the expected depreciation rate from period $t$ to $t+1, i_{t}$ is the domestic interest rate and $i_{t}^{*}$ is the foreign interest rate.

Assume that in the long run the current account $(c a)$ depends on the deviation from PPP, whereas the capital account $(k a)$ depends on the deviation from UIP, that is, deviations from the nominal

\footnotetext{
${ }^{2}$ Since we use price indices in the estimation, we focus on testing relative PPP.

${ }^{3}$ In a recent study, Murray and Papell (2002) also find the half-life of deviations from PPP for each of 20 countries (including Norway) to lie between 3 and 5 years. However, their confidence intervals are much larger than previously reported, implying in fact that univariate methods provide virtually no information regarding the size of the half-life.
} 
interest differentials adjusted for expected exchange rate changes. The balance of payment then implies that

$$
c a_{t}+k a_{t}=\gamma\left(v_{t}+p_{t}^{*}-p_{t}\right)+\lambda\left(i_{t}-i_{t}^{*}-\Delta v_{t+1}^{e}\right)=0
$$

where $\gamma$ captures the elasticity of net exports with respect to competitiveness and $\lambda$ represents the mobility of international capital (where $\lambda \rightarrow \infty$ so that $g_{t}^{e}=0$, if capital is perfectly mobile). Assuming that in equilibrium $\Delta v_{t+1}^{e}=0$, (4) can be solved for the exchange rate to yield a long-run equilibrium relationship

$$
v_{t}=p_{t}-p_{t}^{*}-v\left(i_{t}-i_{t}^{*}\right)
$$

where $v=\lambda / \gamma$. Equation (5) states that the nominal exchange rate is a function of both the price level differential and the interest rate differential, where the speed of adjustment to the interest rate differential is given by $v$. Another way to interpret (5) is that the non-stationarity of the real exchange rate $\left(v_{t}-p_{t}+p_{t}^{*}\right)$ can be removed by the non-stationarity of the interest rate differential $\left(i_{t}-i_{t}^{*}\right)$.

\section{ECONOMETRIC MODEL}

Here we model the whole system jointly within a full-information maximum-likelihood (FIML) framework (see Johansen, 1988). We first define the vector stochastic process as $z_{t}=\left(v_{t}, p_{t}, p_{t}^{*}, i_{t}\right.$, $\left.i_{t}^{*}\right)$, where $v, p, p^{*}, i$ and $i^{*}$ are defined as above. This process can be reparameterized as a vector equilibrium correction model (VEqCM).

$$
\Delta z_{t}=\mu+\Gamma_{1} \Delta z_{t-1}+\Gamma_{2} \Delta z_{t-2}+\ldots+\Gamma_{p-1} \Delta z_{t-p+1}+\Pi z_{t-1}+\Psi S_{t}+u_{t}
$$

where $u_{t} \sim \operatorname{NIID}(0, \Sigma) . \mu$ is a vector of constants and $S_{t}$ is a vector of unrestricted centred seasonal dummies. The null hypothesis of $r$ cointegrating vectors can then be formulated as

$$
H_{0}: \Pi=\alpha \beta^{\prime}
$$

where $\alpha$ and $\beta$ are $5 \times r$ matrices of rank $r,(r<5), \beta^{\prime} z_{t}$ comprises $r$ cointegration $I(0)$ relations and $\alpha$ contains the loading parameters. In the following analysis we first estimate the number of cointegrating relations in a well-specified $\mathrm{VEqCM}$. Thereafter, we test the following hypotheses on the cointegration vector $\beta^{\prime}$ : stationarity of the real exchange rate, (that is, if PPP holds), stationarity of the interest rate differential and finally a combination of these hypotheses.

\section{Estimating the long-run relationship ${ }^{4}$}

The variables used in the econometric analysis are the log of the nominal exchange rate in Norway relative to its trading partners $(v), \log$ of home $(p)$ and foreign (trade weighted) consumer prices $\left(p^{*}\right)$, and home $(i)$ and foreign (trade weighted) interest rates $(i *)$. In addition, a constant and centred

${ }^{4}$ The empirical estimations are conducted using PcGive 10; see Doornik and Hendry (2001). 
seasonal dummies are included in the estimation as unrestricted variables. ${ }^{5}$ All data are taken from KVARTS database, Statistics Norway. We use quarterly data, and the estimation period is 1983Q1-2002Q2. The start date for estimation is set to exclude the turbulence in the international capital markets in the early 1980s, which would necessitate a series of intervention dummies that we try to avoid (see the discussion in MacDonald and Marsh, 1999). Unit root tests show that it is reasonable to assume that all variables are integrated of first order, $I(1)$, and we can reject the hypothesis of integration of second order, $I(2){ }^{6}$

Estimating a VAR with four lags, ${ }^{7}$ the cointegration tests indicate one cointegration vector at the 1 percentage significance level (the Trace test for ' $H_{0}$ : No cointegration', yields a test statistic of 91.88 [0.00], where the significance probability of acceptance is in brackets). Testing restrictions on $\beta$, we can reject the hypothesis of pure PPP and interest rate differential (based on pure UIP) (LR test $\chi^{2}(4)=35.72[0.00]$ and $\chi^{2}(4)=18.58[0.00]$ respectively). However, neither of these two hypothesis can be rejected when the rest of the cointegrating vectors are left unrestricted, implying that the hypotheses of PPP and UIP should be combined. In the end, a cointegration vector with PPP augmented with the interest rate differential cannot be rejected $\left(\chi^{2}(3)=6.01[0.11]\right)$. This fully restricted vector has the expected signs; if the Norwegian interest rate is high (relatively to the interest rate of Norway's trading partners), the equilibrium real exchange rate must be low, consistent with an appreciation of the Norwegian krone.

The restricted $\beta$ vector is finally combined with weak exogeneity restrictions on foreign prices and domestic and foreign interest rates. This specification is not rejected $\left(\chi^{2}(6)=11.0\right.$ [0.09]). The additional restrictions do not change the estimated long-run coefficients much. The estimated longrun exchange rate relation is reported in equation (8), with standard error in parenthesis below.

$$
v=p-p^{*}-\underset{(1.55)}{9.99(i-i *)}
$$

Equation (8) clearly implies that although PPP is not by itself a stationary process, it becomes stationary when combined with the interest rate differential. Hence, the long-run interactions between the goods and capital markets cannot be ignored.

In the analysis we have used quarterly interest rates. To get a proxy for the annual interest rate, we therefore need to multiply the quarterly interest rate by four. Hence, if we had used an annual interest rate, the coefficient for the interest rate difference would be $1 / 4$ of the one reported in (8), i.e. about 2.5. This is somewhat larger than what was reported in a related study by Bjørnland and Hungnes (2002), ${ }^{8}$ but may reflect the fact that in 2001 Norway formally adopted a new monetary policy regime, where rather than targeting the exchange rate the inflation rate is now targeted. The perceived effect of the interest rate differential on the exchange rate may therefore have changed since 2001. This may just have been captured given that we now have a longer sample (ending in 2002 rather than in 1999 as in Bjørnland and Hungnes, 2002).

\footnotetext{
${ }^{5}$ The estimated vector autoregressive model used for the cointegrating analysis does not include any dummies, as none are needed to satisfy the misspecification tests. However, in the parsimonious representation in the next section, we will use an outlier detection procedure to suggest additional dummies.

${ }^{6}$ These and the other test results reported below can be obtained from the authors on request.

${ }^{7}$ Four lags were necessary to exclude any problem with autocorrelation; however, using instead three or two lags, the results from the cointegration analysis are virtually unchanged.

${ }^{8}$ Bjørnland and Hungnes (2002) also included the real oil price and a trend (the latter restricted to lie in the cointegration space) in the model, but both came out as insignificant.
} 


\section{A PARSIMONIOUS REPRESENTATION}

The next step after determining the long-run equilibrium relationship is to establish a parsimonious representation for the exchange rate that includes the long-run equilibrium. The econometric methodology used here is a general-to-specific approach. The familiar equilibrium correction form of the exchange rate can be written as

$$
\begin{aligned}
\Delta v_{t}= & \sum_{j=1}^{p-1} \gamma_{1 j} \Delta v_{t-j}+\sum_{j=0}^{p-1} \gamma_{2 j} \Delta p_{t-j}+\sum_{j=0}^{p-1} \gamma_{3 j} \Delta p_{t-j}^{*}+\sum_{j=0}^{p-1} \gamma_{4 j} \Delta i_{t-j}+\sum_{j=0}^{p-1} \gamma_{5 j} \Delta i_{t-j}^{*} \\
& +\rho_{1}\left(v-p+p^{*}\right)_{t-1}+\rho_{2}\left(i-i^{*}\right)_{t-1}+\phi D_{t}+\varepsilon_{t}
\end{aligned}
$$

where $p=4, D_{t}$ contains all the deterministic components (constant, centred seasonal dummies and impulse dummies). The exchange rate model therefore contains three lags of the difference of each of the variables of our model; exchange rate, domestic and foreign prices and domestic and foreign interest rates. In addition, the equilibrium correction term is included, lagged one period. The equilibrium correction term is the same as that specified above, but rather than imposing one cointegrating vector consisting of PPP and the interest rate differential together, we split the cointegration vector into two parts: pure PPP and the interest rate differential. The data will then determine if they are significant together, which will be a test of the above results.

We first test the unrestricted model for potential misspecifications to ensure data coherence. If that is satisfied, the model is simplified by eliminating statistically insignificant variables. Simplification from the general to specific model is performed using PcGets 1.02 (see Hendry and Krolzig, 2001). Note also that now we allow for impulse dummies, which are chosen by the model based on an outlier detection procedure (rather than imposed by us a priori). ${ }^{9}$ Given that the reduction does not yield any invalid simplification, the final choice will not lose any significant information about the relationship for the data sample that is available. The final choice therefore parsimoniously encompasses the unrestricted model and is not dominated by any other model. The reduction procedure yields the model presented in equation (10), with standard errors in parentheses below the coefficient estimates.

$$
\begin{aligned}
& \Delta v_{t}=\underset{(0.04)}{0.21}+\underset{(0.26)}{1.25} \Delta p_{t}+\underset{(0.25)}{0.65} \Delta p_{t-2}-\underset{(0.41)}{1.56} \Delta p_{t}^{*}-\underset{(0.41)}{1.31} \Delta p_{t-3}^{*}+\underset{(0.73)}{2.72} \Delta i_{t}-\underset{(1.09)}{2.47} \Delta i_{t-2}^{*}
\end{aligned}
$$

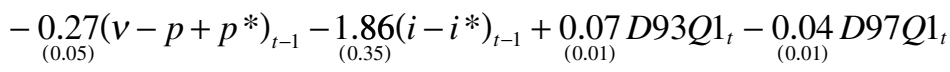

$$
\begin{aligned}
& -\underset{(0.01)}{0.05} D 02 Q 2_{t}+\underset{(0.004)}{0.01} S_{t}+\hat{\varepsilon}_{t}
\end{aligned}
$$

The model shows that the coefficients in front of PPP and the interest rate differential are highly significant, and should therefore be combined as suggested by the cointegration analysis. Dividing the coefficient on the interest rate term on that in front of PPP yields a coefficient of 7, which is close to the one reported in the cointegration analysis in (8).

In addition, contemporaneous and lagged values of domestic and foreign prices, a contemporaneous value of the domestic interest rate, a lagged value of foreign interest rate, a centred seasonal dummy $(S)$ and the three detected impulse dummies; 1993Q1, 1997Q1 and 2002Q2, are found to be

\footnotetext{
${ }^{9}$ We specify the outlier detection size of the marginal outlier (in standard deviation) to be 1.9 in PcGets, (the default is 2.56 ). 
Table I. Misspecification tests

\begin{tabular}{lrc}
\hline & Value & Significance probability \\
\hline$F_{\text {Chow (1992:4) }}$ & 1.01 & 0.49 \\
$F_{\text {Chow (2000:3) }}$ & 0.54 & 0.80 \\
$\chi_{\text {Normality test }}^{2}$ & 5.01 & 0.08 \\
$F_{\text {AR 1-4 test }}$ & 1.74 & 0.15 \\
$F_{\text {ARCH 1-4 test }}$ & 1.30 & 0.28 \\
$F_{\text {Hetero test }}$ & 20.07 & 0.45 \\
\hline
\end{tabular}

Notes: Chow (1992:4) and Chow (2000:3) are the breakpoint tests, where the first period test fraction is chosen by PcGets at the periods 1992Q4 and 2000Q3 respectively; the normality test checks whether the residuals are normally distributed; $A R$ $1-4$ is a test of 4th-order residual autocorrelation, $A R C H ~ 1-4$ is a test for 4 th-order autoregressive conditional heteroscedasticity in the residuals; and Hetero test is a test for residual heteroscedasticity (see Hendry and Krolzig, 2001).

significant. Interestingly, the dummies in 1993 and 1997 correspond well with the chosen dummies in Bjørnland and Hungnes (2002), and represent respectively a change to a floating exchange rate regime in December 1992/January 1993 after a period of speculation, and a severe appreciation pressure against the Norwegian krone in the first quarter of 1997. The final dummy in 2002Q2 is chosen by the model to account for the severe appreciation of the Norwegian krone in excess of its fundamentals. As mentioned above, it is only recently that Norway adopted the new monetary policy regime of inflation stabilization, so that the expectation formation may not have changed accordingly.

The model implies that the short-run price elasticities are higher than unity, which is consistent with overshooting. In particular, higher domestic prices and interest rate will cause the exchange rate to depreciate in the short run, and a higher foreign price and interest rate will imply an appreciation of the exchange rate. Historically, Norges Bank has increased the interest rate when there has been a depreciation pressure, and reduced the interest rate when there was an appreciation pressure. An increase in the interest rate differential has therefore often coincided with a weaker exchange rate (see Norges Bank, 2000, p. 16). In the long run, however, the exchange rate will eventually move towards equilibrium. The equilibrium correction terms have the expected sign, so that the exchange rate adjusts in the right direction.

No misspecification test rejects the selected model (see Table I), and underlines that the parameters are constant. The model is also congruent, and provides a parsimonious representation for the exchange rate.

Recursive graphics are shown in Figures 1 and 2. Figure 1 emphasizes that most coefficients seem constant, although some are significant only at the end of the sample (for instance, the coefficient for $\Delta p_{t-2}$ ). The equilibrium correction terms are clearly significant and seem fairly stable.

Figure 2 reports the constancy statistics. The upper left panel shows the RSS at each observation and the upper right panel shows the one-step residuals plotted with two standard error bands on either side of zero. Thus any observation outside the band represents an outlier. Note that the model residuals are graphed until 1988, after which the one-step recursive prediction errors are plotted. Clearly there are three large observed outliers throughout the sample, in 1993, 1997 and 2002, and two minors, in 1988 and in 1998/1999. The three large outliers are picked up by three outlier 



Figure 1. Recursive least squares: parameter constancy graphs

dummies in the model (see the discussion above), and used in the final estimation that covers the whole period. The band itself seems fairly constant.

The Chow test is graphed in the bottom left panel of Figure 2 and the associated $p$-values (with the $5 \%$ critical value shown as a straight line) are shown in the bottom right panel. Both of these panels confirm the constancy of the model, since virtually all observations lie above the $5 \%$ critical value.

Finally, Figure 3 shows the actual residuals (estimated non-recursively). The graph emphasizes the constancy of the model when all three dummies are included in the estimation.

\section{OUT-OF-SAMPLE FORECASTING}

Having identified a parsimonious model for the exchange rate, a natural question to ask would be whether the structural model identified here can outperform the random walk in predicting the exchange rate. The random walk model would take the form

$$
v_{t}=v_{t-1}+\varepsilon_{t}
$$

which implies that the best prediction for the exchange rate next period would be the same as this period's exchange rate. 

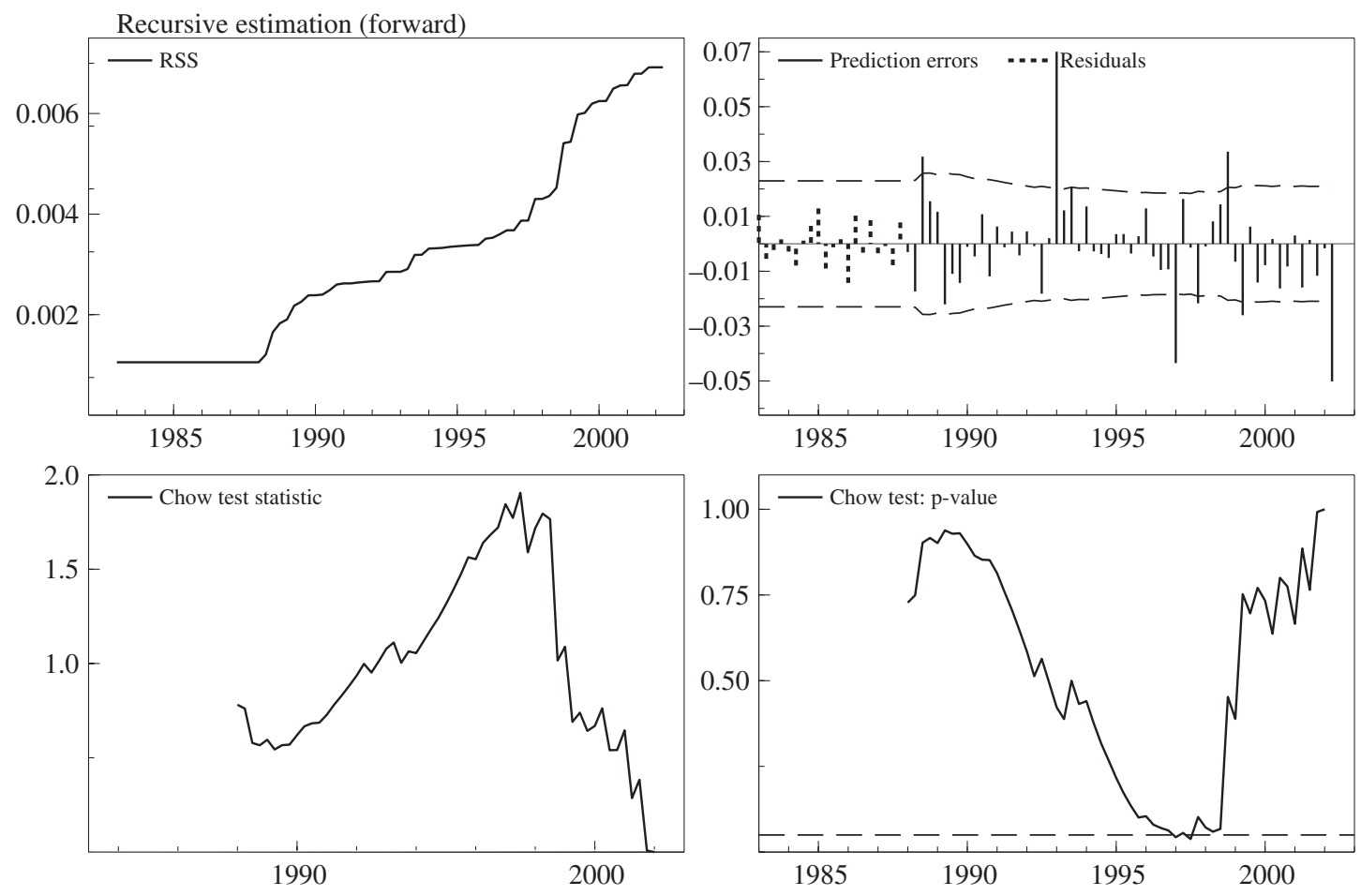

Figure 2. Recursive least squares: constancy statistics

In addition to our structural model, we also estimate an alternative fundamental EqCM, where the equilibrium term is now simplified to a pure PPP $\left(v-p+p^{*}\right)$. The interest rate differential is only allowed to matter in the short run. The model is denoted PPP. The motivation for doing so is to investigate the importance of the interest rate differential for exchange rate determination in the long run. The long-run effect of the interest rate differential on the exchange rate has not been emphasized as important in recent studies of the Norwegian exchange rate behaviour-see, for example, Norges Bank (2000), ${ }^{10}$ Akram (2000) or Bernhardsen and Røisland (2000)—with the recent exception of Naug (2004), who finds the interest rate differential to matter in the long-run relationship for the years 1999-2003, thereby supporting our results for this specific period. ${ }^{11}$ Note that in this forecasting competition all models are compared using levels on the left-hand side, so that it is the forecast of (the log of) the actual exchange rate (and not its change) that are compared.

Following Meese and Rogoff (1983), we perform an out-of-sample forecasting exercise comparing the structural models to a random walk, using a rolling regression methodology. That is, the models are first estimated using data up until the first forecasting period. We take the first 15 years

\footnotetext{
${ }^{10}$ In Norges Bank (2000, p. 16), the Central Bank writes: 'Higher interest rates normally make krone positions more attractive. The isolated effect of changes in interest rate differentials may, however, be limited in relation to other factors.'

${ }^{11}$ The model is also presented in Norges Bank (2003).
} 


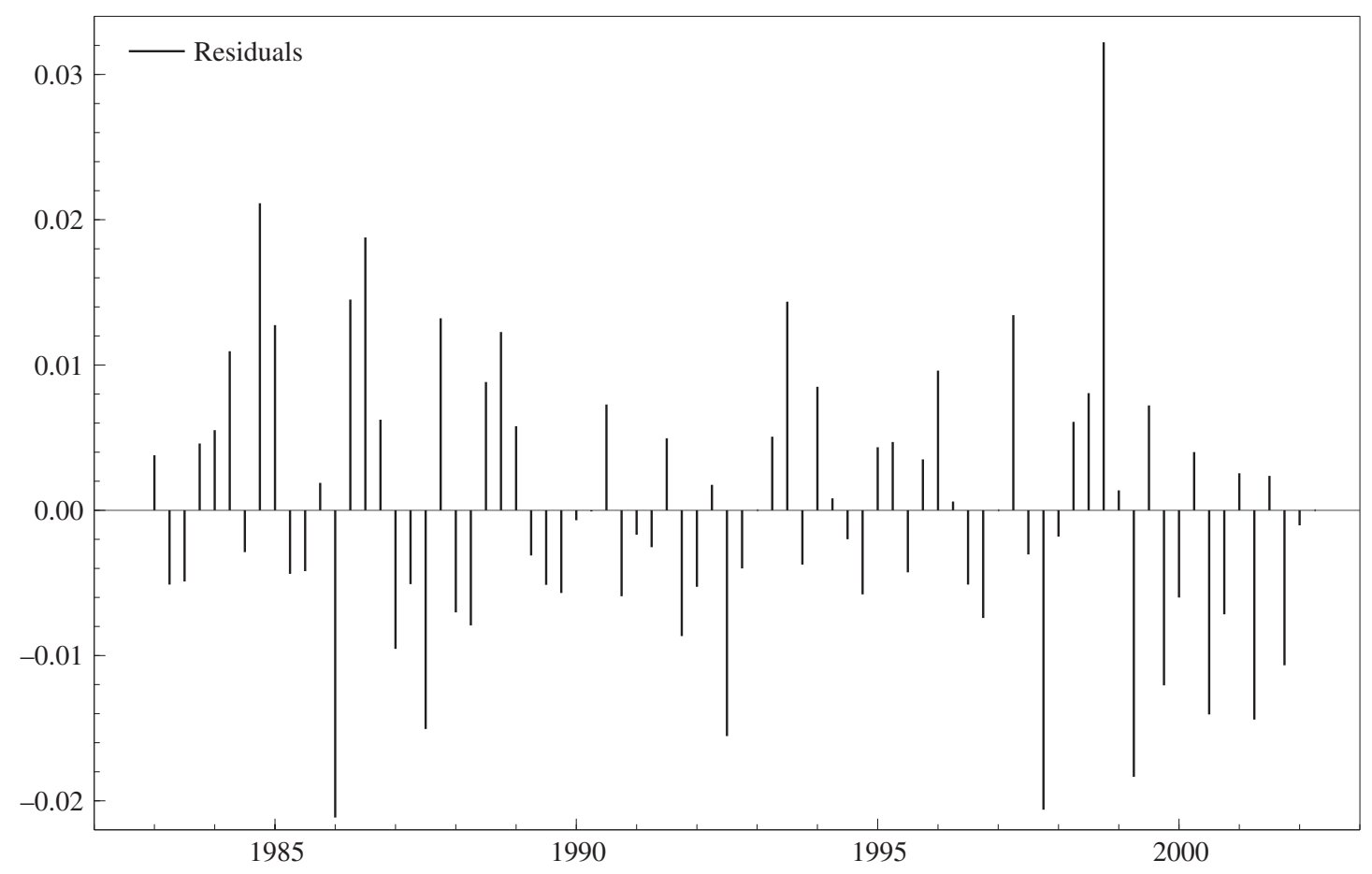

Figure 3. Actual residuals for the relative change in the exchange rate

(1983Q1-1997Q4) as the initial estimation period, which leaves us with a forecast period of almost 5 years (1998Q1-2002Q2). The forecasts are generated at one, two, three and four quarters. These horizons are common in the literature and correspond well with the duration of standard forward contracts (see Meese and Rogoff, 1983). In the next step, the estimation period is rolled forward by one quarter, keeping the total length of the estimation period (15 years) fixed. ${ }^{12}$ New forecasts are then generated at one, two, three and four quarters, and so on. In the end, the squares of the forecast errors at the different horizons are averaged using the root mean square error (RMSE) and the mean absolute error (MAE). RMSE will be our principal criterion used for comparing forecasts. However, in some cases, MAE may be more appropriate than RMSE, in particular if the exchange rate follows a non-normal stable Paretian process with infinite variance, or if the exchange rate distribution has fat tails but finite variance (see Meese and Rogoff, 1983).

The evidence using the RMSE metric is reported in Table II and suggests that the structural EqCM model performs better than the random walk at forecasting the exchange rate at all horizons. The pure PPP model performs worst of all the three models at all horizons, and can therefore not outperform any other model in this forecasting competition.

Although the structural EqCM model performs better than the random walk at all horizons, the relative difference between them is larger at the short horizon than at the long horizon (such as 1

\footnotetext{
${ }^{12}$ Of course, that is only important for structural models, since the random walk model uses the last observation when making forecasts.
} 
Table II. Root mean square error (RMSE) $(* 100)$

\begin{tabular}{lccc}
\hline Horizon (quarters) & RW & EqCM & PPP \\
\hline 1 & 2.17 & 1.82 & 2.19 \\
2 & 3.33 & 2.64 & 3.65 \\
3 & 3.98 & 3.43 & 4.71 \\
4 & 4.45 & 4.06 & 5.68 \\
\hline
\end{tabular}

Table III. Mean abolute error $(\mathrm{MAE})(* 100)$

\begin{tabular}{lccc}
\hline Horizon (quarters) & $\mathrm{RW}$ & $\mathrm{EqCM}$ & $\mathrm{PPP}$ \\
\hline 1 & 1.79 & 1.27 & 1.80 \\
2 & 2.52 & 2.19 & 2.87 \\
3 & 3.11 & 2.98 & 4.01 \\
4 & 3.48 & 3.66 & 4.86 \\
\hline
\end{tabular}

year). This is at odds with other similar studies, e.g. Reiton and Ongena (1999), but may be due to the fact that our structural model has a dummy in the last observation (2002Q2), which is ignored in the forecasting competition. Hence, predictions using a forecast horizon of four quarters, where we will have fewer observations to base our forecast on than using, for instance, a one-quarter horizon, will be dominated by the prediction failures at the end of our sample.

The evidence using the MAE metric (see Table III) strengthens the results reported above. The structural EqCM performs the best of all the models at all horizons, with the exception of the horizon of four quarters, where the random walk model performs marginally better. The pure PPP model again performs the worst, as it cannot outperform any other model at any horizon. The reason that the structural EqCM performs marginally worse than the random walk model at the four quarter horizon may, as we discussed above, be due to the fact that we have relatively few observations at this horizon, so that they will be dominated by the prediction failures at the end of our sample. Nevertheless, the results emphasize the importance of the interest rate differential in the long run when predicting exchange rate behaviour, as in no case does the pure PPP-model outperform any other model.

\section{CONCLUSION}

This paper has examined whether a parsimonious dynamic exchange rate model for Norway that combines the purchasing power parity condition with the interest rate differential in the long run can outperform a random walk model in an out-of-sample forecasting exercise.

We show that the long-run results can be embedded in a parsimonious representation, which outperforms a random walk in an out-of-sample forecasting competition. Ignoring the long-run interest differential (that is, focusing only on PPP in the long run), however, the fundamental model can no longer outperform a random walk.

The results emphasize the importance of the interest rate differential in the long run when predicting exchange rate behaviour, as in no case does a pure PPP model outperform any other 
model. In fact, an economic modeller that ignores the long-run effect of the interest rate differential on the exchange rate and focuses instead only on PPP in the long run would be much better off had she instead used a random walk model for the exchange rate when making an economic forecast.

\section{ACKNOWLEDGEMENTS}

The authors wish to thank $\AA$. Cappelen, P. R. Johansen, B. E. Naug and T. Skjerpen for very useful comments and discussions. The usual disclaimers apply.

\section{REFERENCES}

Akram QF. 2000. PPP despite real shocks: an empirical analysis of the Norwegian real exchange rate. Working Paper 2000/7, Norges Bank.

Alexius A. 2001. Sources of real exchange rate fluctuations in the Nordic countries. Scandinavian Journal of Economics 103: 317-331.

Bernhardsen T, Røisland Ø. 2000. Hvilke faktorer påvirker kronekursen? Penger og Kreditt, Norges Bank, 3/2000; 187-194 (in Norwegian).

Bjørnland HC, Hungnes H. 2002. Fundamental determinants of the long run real exchange rate: the case of Norway. Discussion Paper 326, Statistics Norway.

Chortareas E, Driver RL. 2001. PPP and the real exchange-rate interest rate differential puzzle revisited: evidence from non-stationary panel data. Working Paper 138, Bank of England.

Chrystal KA, MacDonald R. 1995. Exchange rates, financial innovation and divisia money: the sterling/dollar rate 1972-1990. Journal of International Money and Finance 14: 493-513.

Doornik J, Hendry DF. 2001. Econometric Modelling using PcGive. Timberlake Consultants: London.

Engel C. 1996. The forward discount anomaly and the risk premium: a survey of recent evidence. Journal of Empirical Finance 3: 123-192.

Frankel JA, Rose AK. 1996. A panel project on purchasing power parity: mean reversion within and between countries. Journal of International Economics 40: 209-224.

Fritsche CP, Wallace M. 1997. Forecasting the exchange rate PPP versus a random walk. Economic Letters 54: 69-74.

Hendry DF, Krolzig H-M. 2001. Automatic Econometric Model Selection Using PcGets. Timberlake Consultants: London.

Holmes MJ. 2001. New evidence on real exchange rate stationarity and purchasing power parity in less developed countries. Journal of Macroeconomics 23: 601-614.

Johansen S. 1988. Statistical analysis of cointegration vectors. Journal of Economic Dynamic and Control 12: 231-254.

Johansen S, Juselius K. 1992. Testing structural hypotheses in a multivariate cointegration analysis of the PPP and the UIP for UK. Journal of Econometrics 53: 211-244.

Jore AS, Skjerpen T, Swensen AR. 1998. Testing for purchasing power parity and interest rate parities on Norwegian data. In LINK Proceedings 1991-1992 (Studies in Applied International Economics), Vol. 1. World Scientific Publishing: Singapore; 60-80.

Juselius K, MacDonald R. 2000. International parity relationships between Germany and the United States: a joint modelling approach. Discussion Paper 00/10, University of Copenhagen, Institute of Economics.

Kim BJC, Mo S. 1995. Cointegration and the long-run forecast of exchange rates. Economics Letters 48: 353-359.

MacDonald R, Marsh IW. 1997. On the fundamentals and exchange rates: a Casselian perspective. Review of Economics and Statistics 79: 655-664.

MacDonald R, Marsh IW. 1999. Exchange Rate Modelling, Kluwer: Boston, MA.

MacDonald R, Taylor MP. 1994. The monetary model of the exchange rate: long run relationships, short run dynamics and how to beat a random walk. Journal of International Money and Finance 13: 276-290.

Copyright ( 2006 John Wiley \& Sons, Ltd.

J. Forecast. 25, 209-221 (2006)

DOI: $10.1002 /$ for 
McNown R, Wallace MS. 1994. Cointegrating tests of the monetary exchange rate model for three high-inflation countries. Journal of Money, Credit and Banking 26: 396-411.

Meese RA, Rogoff K. 1983. Empirical exchange rate models of the seventies: do they fit out of sample? Journal of International Economics 14: 3-24.

Murray CJ, Papell DH. 2002. The purchasing power parity persistence paradigm. Journal of International Economics 56: 1-19.

Naug B. 2004. Factors behind movements in the krone exchange rate: an empirical analysis. In Explaining Movements in the Norwegian Exchange Rate, Eitrheim Ø, Gulbrandsen K (eds). Occasional Papers No. 32, Norges Bank.

Norges Bank. 2000. Inflation Report 3/2000.

Norges Bank. 2003. Inflation Report 1/2003.

O'Connell P. 1998. The overvaluation of purchasing power parity. Journal of International Economics 44: 1-19.

Reinton H, Ongena S. 1999. Out-of-sample forecasting performance of single equation monetary exchange rate models in Norwegian currency markets. Applied Financial Economics 9: 545-550.

Rogoff K. 1996. The purchasing power parity puzzle. Journal of Economic Literature 34: 647-668.

Serletis A. Zimonopoulos G. 1997. Breaking trend functions in real exchange rates: evidence from seventeen OECD countries. Journal of Macroeconomics 19: 781-802.

Authors' biographies:

Hide C. Bjørnland is a postdoc at the Department of Economics, University of Oslo. She holds an MSc in Econometrics from the LSE and a PhD from University of Oslo. Her research interests are in monetary policy, business cycle analysis and applied econometrics.

Håvard Hungnes is a Research Fellow in the Research Department at Statistics Norway and a PhD student at the University of Oslo. His research interests are forecasting, and theoretical and empirical macroeconometrics.

Authors' addresses:

Hilde C. Bjørnland, Department of Economics, University of Oslo, PO Box 1095 Blindern, N-0317 Oslo, Norway.

Håvard Hungnes, Research Department, Statistics Norway, PO Box 8131 Dep, N-0033 Oslo, Norway. 